\title{
O DADO EMPÍRICO DE LINGUAGEM NA PERSPECTIVA DA ANÁLISE DE DISCURSO FRANCESA: UM EXEMPLO SOBRE AS RELAÇÕES DISCURSIVAS ENTRE CIÊNCIA, COTIDIANO E LEITURA*
}

\author{
The language empirical data in the french discourse \\ analysis approach: an example of the discursive relations \\ among science, quotidian and literacy
}

Henrique César da Silva ${ }^{1}$

Camila Raimualdo Baena

Juliana Raimualdo Baena ${ }^{2}$

\begin{abstract}
Resumo: O objetivo deste trabalho é problematizar a questão do dado empírico de linguagem na pesquisa em Educação em Ciências. Isso é feito com base na explicitação dos aspectos centrais de uma importante perspectiva teórico-metodológica do campo da linguagem, surgida na França na década de 1960: a análise de discurso francesa. O foco central recai na questão da não-transparência da linguagem. Como exemplo é apresentada uma análise de discursos que relacionam ciência e cotidiano na escola, hoje. Valendo-se da problematização teórica e desse breve exemplo de análise, são levantadas questões, em aberto, consideradas importantes para serem mais bem debatidas, sobre metodologia de pesquisa na área de Educação em Ciências e sua relação com o ensino propriamente dito.

Palavras-chave: dados empíricos. discurso. linguagem. metodologia de pesquisa. ensino de Ciências.

Abstract: The aim of this work is to discuss issues of language in empirical data in Science teaching research. Such an aim is achieved through the use of core issues within an important methodological language theory that was developed in France around the 1960s: French Discourse Analysis. The central focus is the problem of the non-transparency of language. An analysis of discourses that relate science and the everyday in the school today is presented. After the theoretical investigation and a brief analytical example, a set of still unanswered questions is presented because of their importance in the debate about research methodology in Science teaching and their relationship with teaching itself.
\end{abstract}

Key words: empirical data. discourse. language. research methodology. Science teaching.

* Versão preliminar deste trabalho apresentada na Mesa-Redonda "Metodologia de pesquisa em ensino de Física: uma agenda para debate", IX Encontro de Pesquisa em Ensino de Física, 2004.

${ }^{1}$ Professor, Departamento de Geociências Aplicadas ao Ensino e Programa de Pós-Graduação em Ensino e História de Ciências da Terra, Instituto de Geociências, Universidade Estadual de Campinas. E-mail: henriquecsilva@ige.unicamp.br

${ }^{2}$ Licenciadas em Física pela Universidade Católica de Brasília.E-mails: camila.baena@gmail.com; juliana_baena@ig.com.br 
Silva, H. C. et al.

"Porque é histórico, muda. Porque é histórico, permanece."

Eni Orlandi

\section{Introdução}

A área de pesquisa em Educação em Ciências tem se apoiado em aportes teóricos de diferentes campos de conhecimento, como: História, Filosofia e Sociologia da Ciência, Epistemologia, teorias do Currículo, Psicologia Cognitiva, Educação, Psicanálise. Nas últimas décadas, com base em diferentes necessidades e problemas de pesquisa, diferentes aportes do campo da linguagem também vêm sendo utilizados. Longe de dar uma representação fidedigna da entrada desses aportes do campo da linguagem na área de Educação em Ciências, podemos citar trabalhos como os de Moraes (2003), Colinvaux et al. (2003), Mortimer e Scott (2002), Villani e Nascimento (2003). Entre os diferentes aportes teóricos do campo da linguagem está a linha francesa da Análise de Discurso, utilizada por autores como Ricon e Almeida (1991), Almeida (2004), Souza e Almeida (2002), Silva e Almeida (2005), Nascimento (2005) e Oliveira (2006); e, dentro de uma abordagem teórico-metodológica, caracterizada como estudos do discurso por Martins (2006), trabalhos como os de Martins et al. (2004), Andrade e Martins (2004) e Nascimento e Martins (2005). Esses trabalhos são apenas alguns exemplos do potencial teórico-analítico da $\mathrm{AD}$ francesa para questões pertinentes à Educação em Ciências, sobretudo, se deseja-se compreender aspectos do ensino e da circulação do conhecimento científico, seja dentro, seja fora da escola, como partes do funcionamento histórico-social mais amplo.

De fato, grande parte do material empírico com o qual se trabalha na área de pesquisa em Educação em Ciências é um material de natureza simbólica, constituído por diferentes linguagens, entre elas: a visual, a linguagem matemática, e, sobretudo, a linguagem verbal, seja escrita ou oral. A maioria das pesquisas lidam com falas e escritos de professores e alunos, com materiais impressos, como livros, imagens etc. Do ponto de vista teórico adotado neste trabalho, e que será explicitado a seguir, não seria ousado demais interpretar grande parte da pesquisa realizada no campo da Educação em Ciências como, essencialmente, um trabalho de leitura. E como cada gesto de produção de linguagem também está investido num processo de interpretação, de leitura, este trabalho pode ser interpretado como, basicamente, de interpretação de leituras, ou seja, de leitura de leituras.

Dada a natureza desse material empírico, a natureza desses "dados", a natureza do trabalho de pesquisa na área de Educação em Ciências, torna-se importante refletir sobre metodologia de pesquisa em ensino com base, também, em questões que remetem à linguagem. Qual a natureza desses "dados"?

No entanto, esta questão poderia ser respondida de maneiras diferentes conforme se adotassem diferentes perspectivas teóricas em relação à linguagem, diferentes concepções de linguagem e de discurso. As respostas seriam diferentes conforme se pensasse tomando-se por base a análise de conteúdo, das teorias da enunciação, das diferentes análises de discurso, da análise conversacional, da sociolingüística, da semiótica. Comparar ou confrontar diferentes concepções está fora do alcance deste trabalho. Nossa intenção é tão-somente apresentar a 
contribuição que uma determinada concepção de linguagem e de discurso pode dar para uma abordagem dessa questão. Trata-se da linha francesa da Análise de Discurso (doravante, AD), que se baseia nos trabalhos de Michel Pêcheux, na qual temos procurado subsídios para nosso trabalho já há alguns anos.

E, mesmo situando-nos dentro dessa perspectiva teórico-metodológica específica, a questão da natureza dos dados de linguagem ainda envolveria muitos e complexos aspectos. Por outro lado, nessa mesma perspectiva, um aspecto se torna relevante: a questão da nãotransparência da linguagem.

Primeiramente, apresentamos alguns aspectos centrais da Análise de Discurso francesa, relacionando-os com a questão foco deste trabalho: a não- transparência da linguagem. Em seguida, apresentamos um exemplo de análise, com base nessa perspectiva teórico-metodológica. Essa problematização permitiu-nos, nas discussões finais, levantar questões relativas à metodologia de pesquisa em ensino e sua relação com o ensino propriamente dito.

Tanto a AD quanto outras teorias relacionadas à linguagem vão problematizar a questão da transparência em vários sentidos. $\mathrm{A} \mathrm{AD}$, particularmente, produziu um deslocamento teórico bastante singular na noção de leitura, na relação entre linguagem e exterioridade, ou seja, na noção de sujeito e de situação (ou contexto) e sua relação com a linguagem e, sobretudo, na relação entre linguagem e história (Orlandi, 1999).

\section{O problema da transparência da linguagem}

Mas em que reside o problema da transparência? O problema da transparência pode aparecer de diferentes maneiras, na maioria das vezes implícito, quando trabalhamos com a análise de "dados" de linguagem: quando se considera que falas, textos, imagens, possuam um único sentido; quando se considera que esses objetos simbólicos carregam, transportam sentidos, como se os sentidos estivessem neles fixados; quando se considera que não haveria mediação ${ }^{3}$ teórica nos sentidos que são "captados" pelo pesquisador com base nesses "dados"; e, finalmente, quando se considera que esses dados de linguagem refletem a realidade, ou melhor, deixam-na visível como se ela própria, a linguagem, não existisse, e pudéssemos encontrar o mundo, o sentido, o conteúdo por meio dela. Nestes casos, o trabalho de pesquisa que toma como dados empíricos dados de linguagem não aparece como leitura (no sentido de trabalho de interpretação), mas como constatação de evidências. É fundamentalmente a relação entre linguagem e realidade que está no cerne desse problema.

Aqui, lembramos uma colocação interessante de Ducrot (1984), bastante coerente com a perspectiva teórico-metodológica da AD francesa e que, no mínimo, pode nos deixar pensativos, quando ele diz que o referente do discurso não é a realidade em si, mas o que o discurso institui como sua realidade. ${ }^{4}$

\footnotetext{
3 "Quando falamos em mediação, gostaríamos de dizer que não pensamos essa mediação no sentido de colocar a linguagem como instrumento, mas pensamos, antes, a mediação como relação constitutiva, ação que modifica, que transforma" (Orlandi, 1987, p. 25).

${ }^{4}$ Essa posição é distinta da afirmação relativista extrema ou ontológica de que a realidade não existe.
} 
O problema da transparência da linguagem talvez esteja relacionado a um certo imaginário positivista associado à necessidade que temos de evidências. Como se, para ser científico, fosse preciso tratar os achados analíticos como se eles estivessem lá. Para a AD, a evidência de que o sentido está no texto, na fala, na imagem, já é um efeito do funcionamento da linguagem. Funcionamento que é fundamental e, essencialmente, sócio-histórico e ideológico.

Nesses casos, em que a linguagem é tratada como transparente, é como se se atravessasse a forma para encontrar o conteúdo. Na verdade, desconsidera-se que a forma esteja implicada no conteúdo e vice-versa. Utiliza-se uma metodologia que atravessaria uma janela que seria transparente. O que a Análise de Discurso francesa e outras teorias de linguagem vão buscar restabelecer nas metodologias que delas derivam, mesmo que de formas diferentes, é justamente a opacidade da linguagem, a não separação entre forma e conteúdo.

Do ponto de vista da significação, não há uma relação direta do homem com o mundo, ou melhor, a relação do homem com o pensamento, com a linguagem e com o mundo não é direta, assim como a relação entre linguagem e pensamento, e linguagem e mundo têm também suas mediacões. (Orlandi, 1996a, p. 12)

Trata-se de considerar a materialidade da linguagem. E creio que a AD francesa se distingue neste caso, dentro das críticas à questão da transparência, ao considerar que esta materialidade não é apenas formal (no sentido estrito), mas histórica. Por isso, a $\mathrm{AD}$, quando trata da questão da linguagem verbal, considera igualmente relevante tanto a língua (ou seja, estrutura, forma, no sentido da Lingüística imanente) quanto a história, e constitui um objeto próprio nesse entroncamento: o discurso. Assim, Pêcheux (1997) considera o discurso como, simultaneamente, estrutura e acontecimento.

Para a $\mathrm{AD}$, o discurso não pode ser confundido com a fala, com o texto ou com a imagem. O discurso é um objeto construído pela análise. Ele é produto, e não dado.

E é justamente aí que a $\mathrm{AD}$ nos permite aprofundar a questão da transparência, pois para a $\mathrm{AD}$, o problema da transparência da linguagem ainda se coloca de uma outra forma, relacionada à primeira, que diz respeito ao que a $\mathrm{AD}$ considera como dado, como discutiremos adiante.

Assim, colocado o problema dentro do esboço de uma perspectiva teórica sobre ele e que, na verdade o constitui, ou seja, o problema da transparência no trato com "dados" de linguagem, passamos a aprofundar um pouco essa problemática, apresentando alguns aspectos teóricos da linha francesa da Análise de Discurso, entre eles: a noção de leitura, a noção de sujeito e de situação, e a questão da relação entre discurso e história.

\section{A noção de leitura e as relações entre sujeito, discurso e história}

Para compreender melhor a perspectiva da AD sobre a questão, iniciamos pela conjuntura intelectual que lhe dá origem nas décadas de 1960-70.

Há dois aspectos fundamentais dessa conjuntura. O primeiro é o de que a AD nasce fundamentalmente para compreender textos políticos, o que influencia na construção de uma 
teoria sobre a linguagem que tem a questão da ideologia como central. O segundo aponta, nessa conjuntura intelectual, vários trabalhos independentes, e de diferentes perspectivas, que vão colocar em xeque a noção de leitura.

\begin{abstract}
Althusser, na retomada de Marx (ler O capital), on Lacan, na leitura de Freud, mostram que a 'leitura' é, na realidade, a construção de um dispositivo teórico (uma teoria) que tem como efeito aprofundar, radicalizar - numa postura que separa revisionistas e não-revisionistas - 0 dito no texto re-significado (interpretado).

Em Barthes, a leitura aparece fundamentalmente como uma (re)escritura. E em Foucault, a leitura é arqueologia (passagem do documento a monumento). (Orlandi, 1996a, p. 41)
\end{abstract}

Assim, temos uma conjuntura intelectual que, problematizando a noção de leitura, aponta sua não-transparência, contribuindo para a construção de uma disciplina de interpretação, distinta da hermenêutica e da análise de conteúdo.

Naquela conjuntura intelectual, os sentidos da leitura de Freud produzidos por Lacan e da leitura de Marx produzidos por Althusser, os sentidos de seus textos, não são "captados", ou "decodificados", não estão em seus próprios textos fixados, mas foram produzidos numa relação com os textos mediada por um certo dispositivo teórico (Orlandi, 1994), ou seja, um dispositivo de leitura.

É justamente a questão da transparência da linguagem, do texto, que está em jogo nesse deslocamento da noção de leitura. Ler é construir um dispositivo teórico.

O filósofo Pêcheux, um dos nomes fundadores da linha francesa da Análise de Discurso, vai ampliar essa noção de leitura, mostrando que, analogamente, toda e qualquer fala, texto (e, eu acrescentaria, imagem), é produto de uma leitura, é produto de uma interpretação, ou seja, é determinada por um dispositivo (Pêcheux, 1995). Mas qual seria a natureza fundamental desse dispositivo? Aqui, talvez, a AD seja singular ao mostrar que esse dispositivo é fundamentalmente de natureza ideológica. Esse dispositivo, de uma natureza análoga ao inconsciente (o imaginário), porém não psicológico, de um lado, dá uma direção para a leitura, fazendo parecer que esta direção é a única, ou seja, ele apaga o trabalho de interpretação, fazendo parecer que o sentido já estava lá no próprio texto (ou na imagem, ou na realidade), ou que somos a origem do sentido. No entanto, as palavras só fazem sentido porque já têm sentido, e nossa relação com o mundo não é direta, mas passa necessariamente pelo simbólico e, portanto, pela interpretação. Assim, o sentido não tem origem nem neste ato de leitura (que, ideologicamente, não aparece como tal), nem no sujeito empírico que produz o enunciado. " $O$ sentido, para a $A D$, não está fixado a priori, como essência das palavras, nem tampouco pode ser qualquer um: há a determinação histórica" (Orlandi, 1996a, p. 27). A AD trabalha, portanto, suspendendo a evidência (numa atitude antipositivista) para buscar compreender como ela se produz. Ou seja, como se produzem essas evidências inescapáveis de que somos a origem do sentido e de que o sentido está no próprio texto, imagem ou mesmo na própria realidade.

Portanto, a $\mathrm{AD}$ vai tratar fundamentalmente da determinação histórica dos processos de significação. Desse modo, aquele processo de interpretação de que a fala (ou texto, ou imagem) que analiso é produto, e que não aparece como tal, já é um processo histórico, que não teve origem naquele sujeito empírico que produziu a fala ou escreveu o texto, ou produziu a imagem. Como o processo histórico de interpretação foi apagado, esquecido, o sentido parece único, uma 
Silva, H. C. et al.

evidência. Portanto, metodologicamente, a $\mathrm{AD}$ vai sugerir a construção de dispositivos teóricos e analíticos que permitam compreender o processo de produção dessa evidência. Ela o faz, estabelecendo que o sentido sempre pode ser outro, mas não pode ser qualquer um, por conta, justamente, dessa determinação histórica. A dimensão histórica dos discursos é fundamental na $\mathrm{AD}$ e na maneira como ela, particularmente, vai problematizar a questão da transparência da linguagem.

Segundo Orlandi (1996b), "um deslocamento fundamental para a análise de discurso é o que permite passar, no estudo da linguagem, do dado para o fato" (p. 209), reconstituindo a dimensão histórica do dizer. Assim, o que nós chamamos de dado, já é um produto de um processo de interpretação (mesmo que não apareça enquanto tal), um processo não subjetivo, um processo histórico. E, por ser histórico, remonta, portanto, a uma memória. Para a AD, o dizer, além de possuir uma estrutura, é um acontecimento, ou seja, o ponto de encontro entre uma atualidade e uma memória (Pêcheux, 1997). Todo dizer está necessariamente inscrito numa rede de dizeres que constituem a sua significação e sem a qual essa não é possível. Todo dizer se dá numa tensão entre paráfrase e polissemia, na repetição, no deslocamento ou na ruptura em relação a outro dizer que o antecede, que é dito em outro lugar. Essa memória discursiva não é de natureza subjetiva, individual, não é de natureza psicológica. Trata-se de reconhecer teoricamente, e buscar analiticamente, o que já foi dito em outro lugar, outro tempo, e que é constitutivo do que está sendo dito agora, no sentido de sua significação.

E aqui, permitam-nos parafrasear Nietzsche (1968, p. 267), quando ele diz "Contra o positivismo, que pára perante os fenômenos e diæ: 'Há apenas fatos [dados]', eu digo: 'Ao contrário, fatos [dados] é o que não há; há apenas interpretações."

Segundo Orlandi (1996a), "a interpretação está presente em toda e qualquer manifestação da linguagem" (p. 9), e, continua, "O homem não pode, assim, evitar a interpretação, ou ser indiferente a ela. Mesmo que ele nem perceba que está interpretando - e como está interpretando - é esse um trabalbo contínuo na sua relação com o simbólico" (p. 10).

Para a AD, portanto, "não existem dados enquanto tal, uma vez que eles resultam já de uma construção, de um gesto teórico" (Orlandi, 1996b, p. 211). Os dados são os discursos e estes não são objetos empíricos. Em poucas palavras, na perspectiva da $\mathrm{AD}$, os dados de linguagem não são dados dados, mas dados construídos. Assim, leitura (metodologia, análise dos "dados empíricos”) e construção teórica são processos inseparáveis. Toda leitura de um material verbal (ou visual, simbólico em geral) é uma leitura no sentido da construção de um aparato teórico.

Assim, a leitura do pesquisador é construção em relação aos "dados" que toma como material empírico que, por sua vez, sendo dados de linguagem, também são produtos de uma interpretação ideologicamente apagada enquanto tal; e, nesta perspectiva teórico-metodológica, é função das análises reconstituir seu processo de produção. Daí ser central, na AD, a noção de condições de produção.

Do que foi exposto até o momento, teríamos, portanto, dois aspectos implicados na não-transparência da linguagem. Retomando, o primeiro deles reside no fato de que para ler um texto, uma fala, uma imagem, o fazemos com base em um dispositivo teórico, e em pressupostos, já que os sentidos produtos de nossas análises não estão nas falas, nos textos, nas imagens. Neste caso, é necessário explicitar esse dispositivo, admitir que ele não é único e que a sua construção já é um produto das nossas pesquisas. O segundo, reside no fato de que esse texto, fala ou imagem, tomado como dado a ler, interpretar, com base nesse dispositivo, já é, 
por sua vez, produto de um processo de interpretação que, para a $\mathrm{AD}$, é de natureza não consciente (ou, pelo menos, não totalmente consciente) e não individual (ou, pelo menos, não totalmente individual). Daí, ser estritamente necessária, para a $\mathrm{AD}$, a noção de ideologia, ao se considerarem questões de linguagem. Ou seja, supor o papel de um imaginário que não é nem de natureza estritamente psicológica, nem individual, mas de natureza histórico-social. Isso remete a um duplo desafio. Além de explicitar e reconhecer que nossas leituras de dados empíricos de linguagem são efetivamente leituras (no sentido de uma interpretação, entre várias possíveis, que se faz de algum lugar teórico, e, acrescentaria, político), a AD nos coloca o desafio de construir um dispositivo que dê conta da produção dessas evidências, que nos ajude a compreender os processos de leitura dos quais os dados com os quais lidamos já são o produto. Isso "porque, em análise de discurso, não se trabalha com as evidências, mas com o processo de produção das evidências" (Orlandi, 1996b, p. 215).

\section{Um esboço de análise: discursos do cotidiano na escola, hoje}

Amparados nas idéias que buscamos sintetizar anteriormente, apresentamos um esboço de análise de discursos que relacionam ciência, cotidiano e leitura. Nessa análise, buscamos mostrar, essencialmente, como discursos produzidos num lugar/tempo se relacionam com outros discursos produzidos em outros lugares/tempos. Relações não controladas, não previsíveis e que apontam para a complexidade da relação da escola com a leitura num contexto atual em que cotidiano e ciência são relacionados de diferentes maneiras, por diferentes formações discursivas sócio-historicamente determinadas. O trabalho de Nunes (2003), mostrando como ciência e cotidiano são relacionados pela mídia jornalística, levantou-nos a suspeita de que ciência e cotidiano podem estar sendo relacionados de diferentes maneiras na constituição do conhecimento escolar. ${ }^{5}$

Para tal, tomamos um pequeno corpus, constituído de textos produzidos em entrevistas com quatro professores de Física e Biologia, de uma escola do Distrito Federal, sobre o uso de textos em suas aulas, e dois dos textos citados pelos professores nas próprias entrevistas, realizadas por duas alunas de Iniciação Científica.

Vejamos, primeiramente, trechos selecionados das entrevistas:

Que outros livros, textos, fontes de informação você utiliza com seus alunos? Como? Descreva uma situação que tenha lhe chamado a atenção.

[1] Super Interessante e Galileu. Quando é trabalhado algum filme contendo assuntos que podem ser aplicados no cotidiano, ${ }^{6}$ é pedido que os alunos leiam sobre esses assuntos nas revistas. (...) [prof. A]

\footnotetext{
${ }^{5}$ Trata-se de um conjunto mais amplo de análises - iniciado dentro do Projeto "Professor: um sujeito-leitor de ciência", coordenado pela Profa. Dra. Mariza Vieira da Silva (UCB) -, que estamos desenvolvendo e, das quais, a apresentada neste trabalho é apenas um exemplo.

${ }^{6}$ Grifos nossos, que já marcam a perspectiva da nossa leitura.
} 
Silva, H. C. et al.

[2] Uma situação que me chamou atenção foi quando mostrei um vídeo sobre o universo, que passou no Discovery Channel. A partir desse dia, um aluno que não gostava de Física, passou a se interessar devido ao vídeo, pois comecon a ver a Física do cotidiano. Esse aluno mudou sua postura nas aulas. [prof. D]

[3] A situação que me lembro foi quando pedi para que lessem o texto do próprio livro didático "Viajando em segurança na companbia de Newton". Após a leitura, passei o vídeo "Física no trânsito", que a Fiat mandou para as escolas. Surtiu bastante efeito. O trabalho foi feito em grupo e a turma obteve notas satisfatórias. [prof. C]

Você adota algum livro didático ou utiliza para preparar suas aulas? Qual? E por que escolheu esse livro?

[4] O livro adotado é: "Física para o Ensino Médio", dos autores Aurélio Gonçalves Filho e Carlos Toscano, editora Scipione, Volume Único, $1^{a}$ edição. Esse livro foi escolbido, pois fiz uso dele no meu segundo grau e achava bastante interessante as gravuras e textos que abordam bastante o cotidiano. [prof. A]

[5] O motivo pelo qual adotei o GREF, é devido ele ser o melhor livro para trabalhar o cotidiano, além de ser mais acessivel para os alunos, pois é gratuito. [prof. D]

Há outros professores que trabalham com textos na sua escola? $O$ que você acha disso? Você conhece esse trabalho?

[6] O Felipe, de Filosofia, e a Aldenice, de Biologia. É mais eficaz, pois há uma dificuldade em se contextualizar, principalmente na Física. Outro problema é a falta de interdisciplinaridade. O texto ajuda a diminuir esses problemas. O texto também colabora para que o conteúdo seja aplicado no cotidiano, pois o aluno deseja saber se há alguma utilidade naquilo que ele está estudando. Até os professores se interessam em visualizar onde a Física está aplicada no cotidiano. As aulas em que há mais participação são as que envolvem textos do cotidiano. [prof. C]

Segundo Pêcheux (1997), todo enunciado é descritível como uma série de pontos de deriva possíveis, oferecendo lugar para a interpretação. Aos descrevermos esses enunciados, já estamos investindo em uma perspectiva interpretativa, orientada pelo nosso foco de análise, qual seja, as relações entre cotidiano, ciência e leitura, o que determinou a seleção dos trechos das entrevistas. Assim, notamos que, em quase todos eles, quer se refiram a livros didáticos, quer a textos alternativos, aparece a palavra cotidiano. Notamos, também, que outras palavras possuem relações semânticas possíveis com cotidiano, o que demonstra a polissemia dessa palavra: cotidiano no sentido da linguagem dos documentários de TV [2]; cotidiano no sentido

${ }^{7}$ Nomes fictícios. 
de contextualizar [7], cotidiano no sentido de situações corriqueiras, experimentadas diariamente por todos nós, como as situações de trânsito [3]. Tensão entre paráfrase e polissemia; repetição, e, ao mesmo tempo, diferença.

Notemos também, já no fio do discurso, um posicionamento concordante com a idéia de que usar textos alternativos ao livro didático é algo bom, do ponto de vista do ensino de Ciências.

Vejamos em que contexto são produzidos esses textos, já que os enunciados não podem ser isolados nem do contexto imediato (a situação no sentido estrito), nem do contexto sócio-histórico (ou seja, a situação no sentido mais amplo). Pois, como discutimos anteriormente, ao produzirem esses enunciados, os sujeitos estão interpretando, e não o fazem como querem, mas como as condições sócio-históricas o determinam. Estamos interpretando interpretações das relações entre ciência, cotidiano e leitura. Assim, é preciso remeter o dito, não a ele mesmo, mas ao contexto de outros dizeres, ao contexto histórico-social em que são produzidos. Neste caso, estamos buscando compreender o processo de produção desses sentidos, e das próprias enunciações. E fazem parte dessas condições, de modo constitutivo, o contexto imediato e o contexto histórico-social mais amplo, além do próprio texto (sua estrutura, textualidade etc.) e o sujeito (a posição que ocupa para ser sujeito do que diz).

Esses textos foram produzidos num contexto particular cujas características fazem parte de suas condições de produção. Esta escola vinha recebendo regularmente estagiários da Universidade. A mesma Universidade cursada pelas entrevistadoras. Dadas as características do trabalho de supervisão de estágios, do qual o primeiro autor era um dos responsáveis, nossa presença era constante nessa escola há mais de dois anos. O uso de textos alternativos ao livro didático era uma prática presente na maioria das aulas ministradas pelos estagiários na escola, o que significa que a academia valoriza esse tipo de prática pedagógica. Um dos professores entrevistados já tinha, há bastante tempo, a prática de utilização de diversos textos de livros de divulgação científica; desenvolvia práticas de leitura pouco comuns em aulas de Física e, embora interagisse efetivamente pouco com os outros professores da sua área e da sua disciplina, era considerado, pelo corpo docente, como um dos melhores professores da escola ${ }^{8}$. A produção desses textos orais e sua significação se dão, portanto, no contexto imediato e histórico-social de uma relação de assimetria Universidade-Escola, Especialista-Professor, cujo imaginário é constitutivo da posição que os sujeitos ocupam para serem sujeitos do que dizem. Mas apenas a valorização da academia não dá conta da complexidade dessas condições de produção. Seus dizerem não são produzidos apenas porque eles responderam o que supostamente queríamos ouvir (e eles, consciente ou inconscientemente, sabiam disso). Se o responderam dessa forma, é porque, de certo modo, esse ou algum discurso está circulando em outro lugar e tempo que é constitutivo do dizer dos professores. Compreenderemos melhor esses outros aspectos das condições de produção se atentarmos tanto para o corpus oral quanto para os próprios textos escritos que os professores citam, e que materializam, de outra

${ }^{8}$ Informações como essa decorrem da longa interação estabelecida entre professor-supervisor de estágios da Universidade e a respectiva escola, tanto pelo contato pessoal, quanto pelos relatórios dos estagiários, o que tornava o cotidiano daquela escola bastante conhecido. 
Silva, H. C. et al.

forma, as relações estabelecidas entre ciência e cotidiano na escola, pelas práticas de leitura ali instauradas.

Retomemos a associação que esses enunciados produzem entre ciência e cotidiano. Essa vinculação entre ciência e cotidiano não está representada apenas no discurso, como é estabelecida pelos textos que dizem utilizar em suas aulas. Notamos que está relacionada a dois textos bastante diferenciados citados pelos professores, ambos citados como lugar de entrada do cotidiano na sala de aula. Um deles é o GREF (Grupo de Reelaboração do Ensino de Física) ${ }^{9}$. Trata-se de um projeto desenvolvido numa universidade por uma grande equipe, que envolveu pesquisadores e professores universitários e professores do ensino médio. Este projeto se filia a uma concepção de cotidiano veiculada por trabalhos apresentados em eventos e publicações da área de ensino de Física, onde se pode ler, por exemplo, o trecho abaixo:

Um dos aspectos fundamentais na organização do conteúdo da proposta GREF, diz respeito ao papel desempenhado por elementos que, fazendo parte da vida cotidiana dos alunos e professores, são tomados como ponto de partida na estruturação dos diversos conteúdos de Física (Copelli et al., 1993, p. 188).

De fato, no discurso da academia, além da valorização do cotidiano, temos valorizado, também, o uso de textos alternativos ao livro didático e estabelecido essa relação entre leitura, texto (de divulgação), ciência e cotidiano, como exemplificado pelo trecho abaixo:

Este trabalho propõe a utilização de notícias cientificas no ensino de Física do $2^{\circ}$ grau, como recurso de ensino, (...) e capacitar a estabelecer as relações necessárias entre os conteúdos desenvolvidos no programa escolar e os fatos do dia-a-dia (Landerdahl e Terrazzan, 1993, p. 406).

Já o segundo texto citado pelos professores é uma reportagem da revista Veja (Rydlewski, 2004), intitulada "A vida sem fio", então recém-publicada.

Voltemos à descrição. Nesse texto, como é comum em revistas, a imagem ganha um destaque especial e estabelece relações complexas com o texto em termos de layout e textualidade (Figura 1 e demais). A reportagem se refere a objetos do cotidiano, ou que vão estar em nosso (de quem?) cotidiano; objetos "tecnológicos", em particular, os novos equipamentos eletrônicos sem fio ou WI-FI (wireless fidelity). O conhecimento científico propriamente dito aparece em boxes e não compõe o elemento principal do texto. Num layout complexo, uma parte do espectro eletromagnético representado visualmente associa, num texto visual-verbal, diferentes faixas de comprimentos de onda com os objetos que são o tema central do texto e outros objetos tecnológicos "cotidianos" (Figura 2), como radares de trânsito, controles remotos etc.

Se no caso dos textos orais nossa descrição/interpretação foi antecipadamente orientada pelo nosso foco e questão de análise, os pontos de deriva que a leitura dessa reportagem

${ }^{9}$ GREF. Grupo de Reelaboração do Ensino de Física. Física. 3v. São Paulo: Edusp, 2001. 
O dado empírico de linguagem...

nos ofereceu se deram posteriormente e pela nossa própria experiência de leitor de revistas. A leitura que temos feito de diversas revistas aponta para um lugar em que leitura, texto, informação e consumo encontram-se intimamente relacionados. Revistas como essa fazem parte da mídia. E a mídia é o lugar, além de outras coisas, da formação do consumidor, da propaganda de produtos, do marketing e do merchandising.

Assim, podemos notar diversos elementos textuais, verbais ou imagéticos, que vinculam esse texto a uma estratégia "camuflada" de marketing. Ela é produzida numa complexa formação discursiva de textos visuais-verbais ou mesmo audiovisuais. Camuflada porque a revista possui espaços específicos para a propaganda, espaços que parecem, cada vez mais, se confundirem (ou confundirem...).
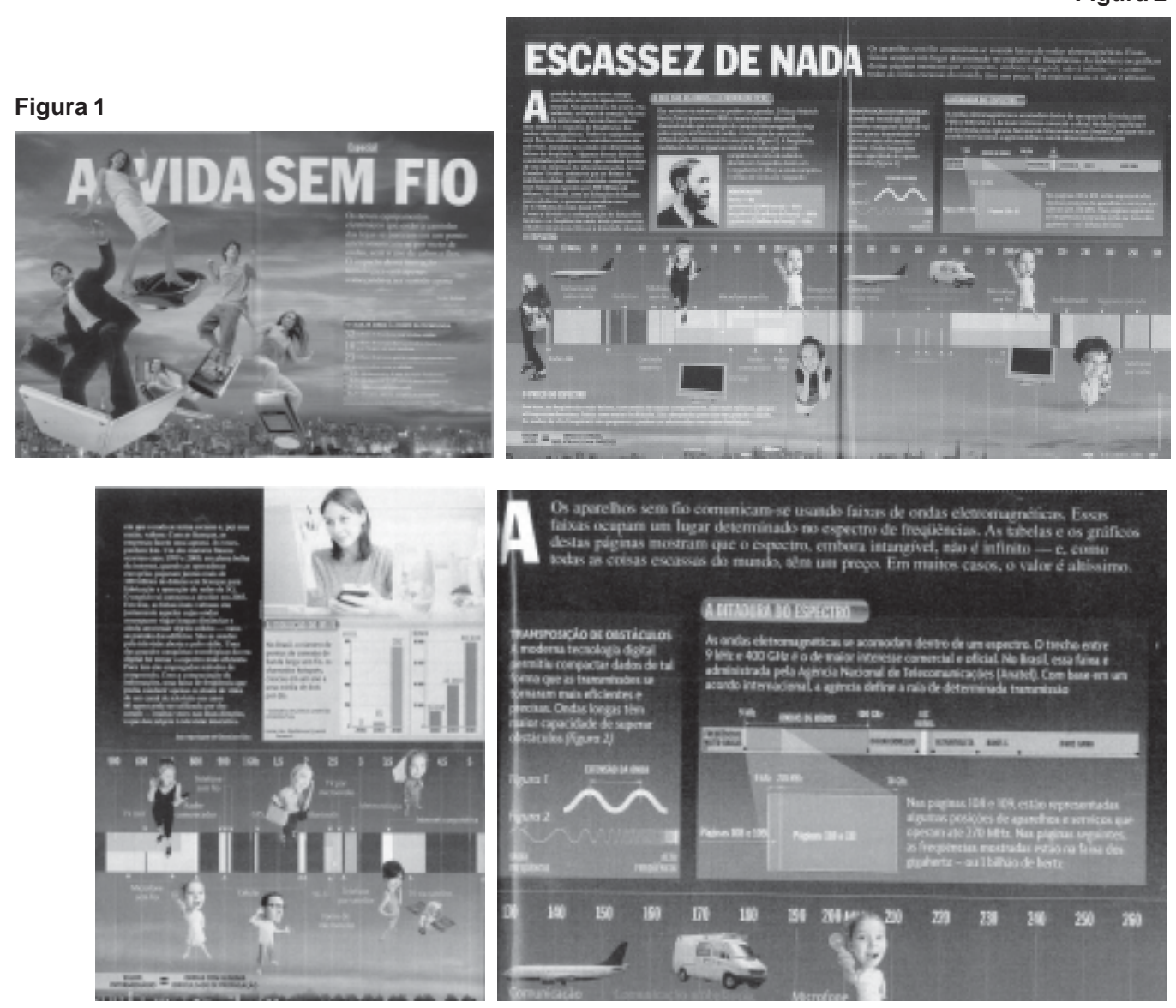

Figura 3

Figura 4

Passando da descrição para a interpretação, ainda que já tenha havido interpretação na descrição, precisamos aprimorar o dispositivo analítico. Segundo Orlandi (1999), "o que define a forma do dispositivo analítico é a questão posta pelo analista, a natureza do material que analisa e 
Silva, H. C. et al.

a finalidade da análise" (p. 27). Já na elaboração das questões da entrevista semi-estruturada, pretendíamos abordar a relação ciência/cotidiano/leitura. No entanto, a relação mídia/consumo, apesar de poder ser pressuposta, neste caso, deparamo-nos com ela a partir do material textual encontrado. Assim, buscando remeter o dito às suas condições de produção e considerando essas condições como estando relacionadas à nossa formação histórico-social, buscamos um autor que nos propiciasse elementos para interpretação.

Para compreendermos as filiações desse discurso em nossa formação social e ideológica, nos alicerçamos em Santos (2001). Para ele, o consumo mudou de figura ao longo do tempo. Os objetos, no caso da reportagem, os aparelhos eletrônicos sem fio, são objetos "carregando uma ideologia que thes é entregue pelos homens do marketing e do design ao serviço do mercado" (p. 51). De fato, há vários aspectos na textualidade (visual-verbal) dessa reportagem que podem ser caracterizados como peças das técnicas de marketing, como as imagens das pessoas, tipicamente imagens de televisão, de comerciais, de outdoor (Figura 3).

Falava-se, antes, da autonomia da produção, para significar que uma empresa, ao assegurar uma producão, buscava também manipular a opinião pela via da publicidade. Nesse caso, o fato gerador do consumo seria a produção. Mas atualmente, as empresas hegemônicas produzem o consumidor antes mesmo de produair os produtos. Um dado essencial do entendimento do consumo é que a produção do consumidor, hoje, precede à producão dos bens e dos serviços. (...) Daí, o império da informação e da publicidade. (Santos, 2001, p. 48)

E é dentro desse esquema consumo-publicidade-objetos-do-cotidiano que se pode compreender que o sujeito-leitor virtual dessa reportagem é o consumidor, ou seja, esta textualidade visual-verbal, na qual se ligam ciência e cotidiano, é produzida dentro da ideologia do consumo. E é dentro deste esquema que a ligação ciência-cotidiano tem o seu papel, dentro do âmbito mais amplo da chamada sociedade do conhecimento. O conhecimento (várias formas de conhecimento, incluindo o conhecimento científico) é um elemento dentro desse esquema, auxiliar da formação desse consumidor em potencial, assim como as imagens que compõem o texto juntamente com o box "científico", imagens típicas de comercial de televisão, outdoors, peças de marketing (Figuras 2 e 3).

Quanto ao box "científico" (Figura 4), seu funcionamento discursivo nessa textualidade pode ser compreendido, mais uma vez, com a ajuda do pensamento de Santos (2001), quando este afirma que:

Como as técnicas hegemônicas atuais são, todas elas, filhas da ciência, e como sua utilização se dá ao serviço do mercado, esse amálgama produz. um ideário da técnica e do mercado que é santificado pela ciência, considerada ela própria infalivel (p. 51).

O professor, ao propor esse texto da revista Veja (Rydlewski, 2004), realiza um gesto de interpretação sobre a relação ciência/cotidiano, um gesto não consciente, daí o funcionamento ideológico das linguagens pela sua inscrição na história.

Não há dúvida de que tanto há ciência numa geladeira e num chuveiro ${ }^{10}$ quanto num monte de objetos eletrônicos sem fio, mas o fato que queremos apontar é que, na esteira de um discurso, legitimado pela pesquisa acadêmica (os especialistas em ensino de Ciências), como 
não controlamos as formações discursivas nas quais se inscrevem nossos discursos e ações, carrega-se para a escola uma outra relação entre ciência e cotidiano, e, em alguns aspectos, muito distante, e até mesmo oposta à idéia de emancipação, de formação crítica e cidadã que, muitas vezes, sustenta o discurso acadêmico da entrada do cotidiano na sala de aula. O GREF e o texto da Veja são textos escritos com textualidades visuais-verbais completamente diferentes, implicados em diferentes formações discursivas, e, portanto, com filiações ideológicas completamente diferentes, que se homogeinizam na escola, e homogeinizam as múltiplas e complexas relações semânticas, epistemológicas e políticas que podem ser estabelecidas entre conhecimento científico e conhecimento cotidiano que são, segundo Lopes (1999), aspectos constitutivos da constituição do conhecimento escolar.

É interessante notar os cruzamentos de textualidades no jogo vinculado entre a midiatização da escola e didatização da mídia (Guimarães, 2001). Materiais didáticos produzidos recentemente, como o PEC, Projeto Escola e Cidadania (Silva et al., 2000), e o Química e Sociedade (Santos e Mól, 2004), embora vinculados a ideários completamente diferentes daquele que associa ciência-cotidiano-consumo, possuem uma textualidade visual-verbal muito próxima à das revistas semanais como a Veja: o tipo de papel, a impressão colorida, textos em boxes, imagens de objetos e situações "cotidianos", explicações científicas e situações cotidianas, vivenciais. Todos esses elementos são os mesmos nos dois tipos de textos. A revista Veja, assim como vários jornais e revistas pelo país, vêm desenvolvendo, há anos, projetos de aproximação com a escola, produzindo materiais que buscam didatizar o uso de textos jornalísticos. Assim, movimentos discursivos que colocam em relação ciência, cotidiano e leitura parecem não vir só da academia, ou do Estado, pelos documentos curriculares oficiais (Brasil, 2002), mas parecem ser parte de um processo histórico-social mais amplo que necessita ainda ser mais bem compreendido.

\section{Discussão e considerações finais}

Esperamos ter conseguido, no mínimo, apontar uma questão de cunho metodológico que consideramos importante sobre o trabalho com dados de linguagem, qual seja, a questão da não-transparência da linguagem do ponto de vista teórico da AD francesa. Questão esta que consideramos pertinente fazer parte de uma agenda de debates de natureza metodológica na pesquisa em Educação em Ciências. No sentido de adensar a complexidade dessa questão dentro dessa agenda, tecemos essas considerações finais, apontando implicações de ordem metodológica para futuras reflexões e pesquisas.

A análise que apresentamos aponta para o fato de que relações entre ciência e cotidiano vêm sendo estabelecidas tanto por discursos acadêmicos, quanto por discursos produzidos pela mídia. Se, de um lado, a análise mostrou uma aproximação entre práticas e discursos desenvolvidos na escola e práticas e discursos produzidos pela pesquisa acadêmica, por outro lado, mostrou, ainda, que essas práticas desenvolvidas na escola são produzidas numa relação

${ }^{10}$ Exemplos de objetos "cotidianos" trabalhados no GREF. 
Silva, H. C. et al.

também com outros discursos, notadamente com todo um complexo de discursos que hoje se entrelaçam com o discurso científico e relacionam ciência e cotidiano de maneiras muito diferentes, cuja caracterização necessita de outras pesquisas. Esses resultados foram produzidos, fundamentalmente, considerando o pressuposto de que ações e discursos de sujeitos dentro de um contexto histórico determinado lidam com interpretações cujos sujeitos não são a origem e, portanto, não são transparentes para o próprio sujeito.

Se, com base em referenciais teóricos, como a linha francesa da Análise de Discurso, considerarmos a necessidade de pensar a historicidade nas análises da produção dos sentidos que constituem os conhecimentos escolares, então, outras questões podem ser levantadas.

Uma delas diria respeito à historicidade da própria instituição escolar, de seus rituais, procedimentos, do que se constitui como típico da cultura escolar, das posições historicamente constituídas de professor e aluno, que os sujeitos empíricos vêm ocupar, e das práticas que lhe estão associadas. Qualquer mudança que se pretenda em sala de aula implica o deslocamento numa historicidade. Pois, como coloca Orlandi (1987), "e a histórica traz em si a ambigüidade do que muda e do que permanece" (p. 9). Pelo contato permanente que temos estabelecido como professores há vários anos, temos indícios de que os discursos e práticas de uso de textos dos professores entrevistados, provavelmente, não são únicos e nem têm origem naquele momento. No entanto, conhecemos muito pouco a historicidade do cotidiano escolar, da produção do conhecimento escolar, com a qual a pesquisa intenciona contribuir para transformar, sobretudo, o que diz respeito à história da leitura escolar e o uso de textos no ensino de Ciências. A análise que apresentamos parece apontar para formas de textualização do conhecimento escolar que se aproximam da textualização produzida pela mídia jornalística. Estaríamos vivenciando mudanças na história da leitura e da textualização do conhecimento escolar?

Outra questão é se, hoje, não seria preciso considerar a historicidade da nossa própria área na sua relação com a escola e, particularmente, com o ensino de Ciências. Ou seja, o fato de que nossos dizeres de pesquisadores, "especialistas", interferem no dizer, nas ações, na realidade de sala de aula, mesmo que não da maneira como gostaríamos. A questão fundamental parece ser a de que, embora sempre estejamos a lamentar e discutir que a pesquisa em ensino não chega às escolas, parece-nos que, se olharmos de um modo um pouco diferente, veremos que chega sim, e o esboço de análise apresentado aponta para isso. Talvez não como queremos, mas apenas o fato de hoje existirem especialistas em ensino de Ciências, pesquisadores em ensino de Ciências, já desloca e interfere sobre a identidade do professor diante de seu trabalho, de sua profissão, pois, do ponto de vista da $\mathrm{AD}$, não se trata de considerar os sujeitos empíricos, mas as posições-sujeitos instauradas pelo funcionamento dos discursos. E, aqui, remeto ao trabalho de Almeida (2003), quando analisa décadas de discursos prescritivos sobre o trabalho do professor.

Assim sendo, talvez fosse preciso considerar que produzimos discursos ao produzirmos pesquisas, e que o discurso é algo no mundo e cujo processo de funcionamento depende da relação que estabelece com outros discursos (interdiscursividade). Tanto para a AD francesa como para autores como Bakhtin (1995), o discurso "não se situa acima da realidade que representa, mas é um fragmento material da realidade, um fenômeno do mundo exterior" (Cardoso, 2003, p. 120).

Se somos leitores da realidade escolar com pretensões de mudança dessa realidade, os professores que estão na sala de aula também o são e o fazem dentro de um contexto históri- 
co-ideológico constituído por diversos outros discursos, entre eles, diversos discursos que relacionam diferentemente ciência e cotidiano. Portanto, fica ainda em aberto a questão da possibilidade (e, talvez, a da necessidade) de refletirmos sobre a relação entre essas diferentes posições de leitura, sobretudo, quando está em jogo a complexa questão da "transferência" de resultados, procedimentos e princípios de pesquisa para a sala de aula. E creio que isso é uma questão de metodologia de pesquisa.

Se tratar com "dados" de linguagem implica a construção de um dispositivo de leitura, é importante lembrar que o lugar de leitura do pesquisador é necessariamente diferente do lugar de leitura do professor. É preciso considerar se não é essa diferença, ou melhor, que tipo de diferença é essa que talvez esteja implicada na dificuldade de "transferência" da pesquisa em ensino para o ensino propriamente dito.

\section{Agradecimentos}

Agradecemos as valiosas sugestões dos pareceristas, que ajudaram a tornar o texto mais compreensível; à Pró-Reitoria de Pós-Graduação e Pesquisa da Universidade Católica de Brasília (UCB), pelo apoio concedido ao projeto: Professor: um sujeito-leitor de ciência, e à Profa. Dra. Mariza Vieira da Silva (Curso de Letras da UCB), coordenadora desse projeto; aos professores que concederam as entrevistas e ao FAEPEX da PRP da Unicamp, pelo apoio concedido ao projeto de pesquisa a que este trabalho está vinculado.

\section{Referências}

ALMEIDA, M. J. P. M. Discursos da ciência e da escola: ideologia e leituras possíveis. Campinas: Mercado de Letras, 2004.

Meio século de educação em Ciências: uma leitura de recomendações ao professor de Física. 2003. Tese (Livre docência) - Faculdade de Educação, Unicamp, Campinas.

ANDRADE, I. B.; MARTINS, I. Discursos de professores de Ciências sobre leitura. In: ENCONTRO NACIONAL DE PESQUISA EM ENSINO DE FÍSICA, 9., Jaboticatubas, MG. Atas... Jaboticatubas: SBF, 2004. CD-ROM.

BAKHTIN, M. (Volochinov). Marxismo e filosofia da linguagem. 7. ed. São Paulo: Hucitec, 1995.

BRASIL. Ciências da Natureza, matemática e suas tecnologias. Brasília: MEC/SEMTEC, 2002. (PCN + Ensino Médio: orientações educacionais complementares aos Parâmetros Curriculares Nacionais). 
Silva, H. C. et al.

CARDOSO, S. H. B. A questão da referência: das teorias clássicas à dispersão de discursos. Campinas: Autores Associados, 2003.

COLINVAUX, D., CORDERO, S.; DUMRAUF, A. G. Contruyendo puentes y fronteras: caracterización del género discursivo en una clase universitaria de Física. Revista Brasileira de Pesquisa em Educação em Ciências, v. 3, n. 1, p. 58-69, 2003.

COPELLI, C.; LARANJEIRAS, C. C.; SILVA, I. S.; PEREIRA, J. A.; MARTINS, J.; PIASSI, L. P.; PELAES, S. B.; HOSOUME, Y. O cotidiano na estruturação do conteúdo de Física: um pressuposto da proposta GREF. In: SIMPÓSIO NACIONAL DE ENSINO DE FÍSICA, 10., Londrina. Atas... Londrina, SBF, 1993, p. 188-189.

DUCROT, O. Referente. Enciclopedia Einauld - Linguagem - Enunciação. Lisboa: Imprensa Nacional/Casa da Moeda, 1984. v. 2

GUIMARÃES, E. Produção e circulação do conhecimento: estado, mídia, sociedade. Campinas: Pontes, 2001.

LANDERDAHL, M. L.; TERRAZZAN, E. A. Proposta de utilização de notícia científica no ensino de Física do $2^{\circ}$ grau como recurso didático. In: SIMPÓSIO NACIONAL DE ENSINO DE FÍSICA, 10., Londrina. Atas... Londrina: SBF, 1993, p. 406-408.

LOPES, A. C. R. Conhecimento escolar: ciência e cotidiano. Rio de Janeiro: EdUERJ, 1999.

MARTINS, I. Analisando livros didáticos na perspectiva dos estudos do Discurso: compartilhando reflexões e sugerindo uma agenda para a pesquisa. Pro-posições, v. 17, n. 1, p. 117136, 2006.

MARTINS, I.; NASCIMENTO, T. G.; ABREU, T. B. Clonagem na sala de aula: um exemplo do uso didático de um texto de divulgação científica. Investigações em Ensino de Ciências, v. 9, n. 1, artigo 1, 2004.

MORAES, R. Uma tempestade de luz: a compreensão possibilitada pela análise textual discursiva. Ciência \& Educação, v. 9, n. 2, p. 191-211, 2003.

MORTIMER, E. F.; SCOTTT, P. Atividade discursiva nas salas de aula de Ciências: uma ferramenta sociocultural para analisar e planejar o ensino. Investigações em Ensino de Ciências, v. 7, n. 3, artigo 7, 2002.

NASCIMENTO, T. G. Contribuições da análise do discurso e da epistemologia de Fleck para a compreensão da divulgação científica e sua introdução em aulas de Ciências. Ensaio, v. 7, n. 2, 2005. 
O dado empírico de linguagem...

NASCIMENTO, T. G.; MARTINS, I. O texto de genética no livro didático de Ciências: uma análise retórica crítica. Investigações em Ensino de Ciências, v. 10, n. 2, 2005. Disponível em: <http://www.if.ufrgs.br/public/ensino/vol10/n2/v10_n2_a6.html>. Acesso em: 12 mai. 2006.

NIETZSCHE, F. The will to power (WP). Trad. Walter Kaufmann and R.J. Hollingdale. New York: Vintage, 1968. (sec. 481).

NUNES, J. H. A divulgação científica no jornal: ciência e cotidiano. In: GUIMARÃES, E. (Org.). Produção e circulação do conhecimento: política, ciência, divulgação. Campinas: Pontes, 2003. p. 43-62. v. 2.

OLIVEIRA, O. B. Discursos dos licenciandos em Ciências Biológicas: um caminho para a reflexão sobre a formação de professor-autor. 2006. Tese (Doutorado em Educação) - Faculdade de Educação, USP, São Paulo.

ORLANDI, E. Interpretação: autoria, leitura e efeitos do trabalho simbólico. Petrópolis: Vozes, 1996a.

ORLANDI, E. Discurso: fato, dado, exterioridade. In: CASTRO, M. F. P. (Org.). O método e o dado no estudo da linguagem. Campinas: Editora da Unicamp, 1996b. p. 209-218.

ORLANDI, E. (Org.). Gestos de leitura: da história no discurso. Campinas: Editora da Unicamp, 1994.

PÊCHEUX, M. O discurso: estrutura ou acontecimento. 2. ed. Campinas: Pontes, 1997.

Semântica e discurso: uma crítica à afirmação do óbvio. 2. ed. Campinas: Editora da Unicamp, 1995.

RICON, A. E.; ALMEIDA, M. J. P. M. Ensino da Física e leitura. Leitura: Teoria e Prática, v. 10, n. 18, p. 7-16, 1991.

RYDLEWSKI, C. A vida sem fio. Veja, edição 1974, ano 37, n. 40, 06 de outubro de 2004, p. 100-111.

SANTOS, M. Por uma outra globalização: do pensamento único à consciência universal. 7. ed. Rio de Janeiro: Record, 2001.

SANTOS, W. L. P.; MÓL, G. S. (Coords.). Química e Sociedade. São Paulo: Nova Geração, 2004. (4 módulos)

SILVA, J. A., CUSTÓDIO PINTO, A.; LEITE, C. Projeto Escola e Cidadania. São Paulo: Editora do Brasil, 2000. 
Silva, H. C. et al.

SILVA, H. C.; ALMEIDA, M. J. P. M. O deslocamento de aspectos do funcionamento do discurso pedagógico pela leitura de textos de divulgação científica em aulas de Física. Revista Electrónica de Enseñanza de las Ciencias, v. 4, n. 3, artigo 8, 2005.

SOUZA, S. C.; ALMEIDA, M. J. P. M. A fotossíntese no ensino fundamental: compreendendo as interpretações dos alunos. Ciência \& Educação, v. 8, n. 1, p.97-111, 2002.

VILLANI, C. E.; NASCIMENTO, S. S. A argumentação e o ensino de Ciências: uma atividade experimental no laboratório didático de Física do ensino médio. Investigações em Ensino de Ciências, v. 8, n.3, 2003. Disponível em: <http://www.if.ufrgs.br/public/ensino/vol8/ n3/v8_n3_a1.html>. Acesso em: 12 mai. 2006.

Artigo recebido em janeiro de 2006 e aceito em julho de 2006 